\title{
Crashworthiness analysis of a lock gate impacted by two different river ships
}

\author{
Jean-Claude Rodet ${ }^{1, a}$ and Hervé Le Sourne ${ }^{2}$ \\ 1 ECMT, 90 rue Pierre Brunier, 69300 Caluire, France \\ 2 Principia Marine, 1 rue de la Noë, BP 22212, 44321 Nantes Cedex 3, France
}

Received 3 October 2002, Accepted 6 February 2004

\begin{abstract}
The objective of this paper is to present an analytical model for the crashworthiness analysis of plane lock gates impacted by river ships. The model is able to assess the indentation by the colliding ship at impact point, to detect possible failure in impact vicinity and to estimate the actions on gate bearings. These latter are calculated by assuming the crash to a quasi-static load, and linear reactions distributions along the bearings. The gate geometry, the bow shape of the colliding ship, its initial velocity and the impact location on the gate, are taken into account. The ships are assumed to be quite rigid with respect to the gate. The modeling has been developed with Matlab. Results of impact of one given lock gate with two different ships: a passenger vessel and a carrier, are compared with FEM results. Impact forces and maximum indentation are well matched. Actions on bearings can be locally rather different because of their time dependence and the non-linearity of their distributions.
\end{abstract}

Key words: Lock gates / crashworthiness / analytical analysis / impact force / actions on bearings

Résumé - Analyse de la résistance au choc d'une porte d'écluse heurtée par deux navires fluviaux différents. L'objectif de cet article est de présenter un modèle analytique pour l'analyse de la tenue aux chocs de portes d'écluses planes heurtées par des navires fluviaux. Le modèle permet d'évaluer l'enfoncement de la porte d'écluse au point d'impact, de détecter des ruptures éventuelles dans son voisinage et d'estimer les réactions aux liaisons de la porte. Ces dernières sont calculées en assimilant l'impact, à un chargement quasi-statique et en supposant une distribution linéaire des efforts le long des appuis. La géométrie de la porte, la forme de l'étrave du navire, sa vitesse initiale et la position du point d'impact sont pris en compte par le modèle. Les navires sont supposés suffisamment rigides par rapport à la porte. Ce modèle a été programmé sous Matlab. Les résultats obtenus par ce modèle pour deux types de navire, un navire à passagers et un cargo fluvio-maritime, sont comparés à des résultats éléments finis. Les forces d'impact et les enfoncements maximum coïncident bien. Les actions aux liaisons obtenues par le modèle analytique diffèrent un peu de celles obtenues par éléments finis du fait de leur forte dépendance aux effets d'inertie et de la non-linéarité de leur distribution.

Mots clés : Porte d'écluse / tenue au choc / modèle analytique / force d'impact / actions aux liaisons

\section{Introduction}

Confronted with problems of maintenance of its installations and with a significant increase of the size of ships, Compagnie Nationale du Rhône had to assess the consequences of impact by ships going downstream against lock gates.

The present study comes within the framework of analytical tools development for collision and grounding of ships, performed by among others, Ohtsubo [1], Pedersen [2], Simonsen [3], Wierzbicki [4], Zhang [5],

\footnotetext{
a Corresponding author: jc.rodet@wanadoo.fr
}

and McDermott [6]. It uses, more particularly, results obtained in the study field of minor collisions of bow indentation into ship side, whose structure is rather similar to a plane gate one.

The main assumption, used in these analytical modellings, is the rigidity of the striking ship bow with respect to the struck structure, which is the gate in the present case. This assumption is used here too, and has been rather well validated by FEM results (Rodet [7]), for one particular gate on river Rhône: the gate dissipates 85 to $90 \%$ of initial kinetic energy when it is struck by three different ships: a passenger vessel, a carrier and a barge, at miscellaneous velocities between 1 and $2 \mathrm{~m} . \mathrm{s}^{-1}$. 


\section{Notation}

\begin{tabular}{|c|c|c|}
\hline$\overline{\sigma_{0}}$ & Average flow stress of the material & $\mathrm{MPa}$ \\
\hline$\sigma_{\mathrm{y}}$ & Yield stress of the material & $\mathrm{MPa}$ \\
\hline$\sigma_{\mathrm{u}}$ & Ultimate stress of the material & $\mathrm{MPa}$ \\
\hline$\varepsilon$ & Strain & \\
\hline$\varepsilon_{\mathrm{c}}$ & Critical strain of the material & \\
\hline$m_{\mathrm{p}}$ & Initial fully plastic bending moment & MN.m \\
\hline$m_{0}, M_{0}$ & Average fully plastic bending moments & \\
\hline$\hat{M}_{0}$ & Average fully plastic bending moment per unit length & MN.m \\
\hline$N_{0}$ & Average fully plastic axial force & $\mathrm{MN}$ \\
\hline$x, y$ & Coordinates in the gate plane & \\
\hline$a$ & Width of the considered element (whole gate or initially impacted macro-element) & $\mathrm{m}$ \\
\hline$a_{1}, a_{2}$ & Horizontal distances between impact point and extremities of the considered element & \\
\hline$b$ & Height of the considered element & $\mathrm{m}$ \\
\hline$w(x, y)$ & Deformation perpendicular to the gate plane & $\mathrm{m}$ \\
\hline$\delta$ & Indentation at impact point & $\mathrm{m}$ \\
\hline$t$ & Equivalent gate plating thickness & $\mathrm{m}$ \\
\hline$t_{\mathrm{g}}$ & Girder web thickness & $\mathrm{m}$ \\
\hline$\theta_{i}, \alpha_{i}$ & Plastic hinge rotations & \\
\hline$H$ & One fourth of the developed folding length in a girder & $\mathrm{m}$ \\
\hline$r$ & Bow tip radius & $\mathrm{m}$ \\
\hline$\beta$ & Stem angle & \\
\hline$\varphi$ & Bow half angle & \\
\hline$\mu$ & Friction coefficient between the bow and the gate & \\
\hline$E_{\mathrm{b}}$ & Global bending energy & MJ \\
\hline$E_{\mathrm{gb}}$ & Bending energy in a girder & MJ \\
\hline$E_{\text {gm }}$ & Membrane energy in a girder & MJ \\
\hline$E_{\mathrm{p}}$ & Membrane energy in a plate & MJ \\
\hline$P_{\mathrm{b}}$ & Gate resistance in its global bending mode & $\mathrm{MN}$ \\
\hline$P_{\mathrm{gb}}$ & Girder bending resistance & $\mathrm{MN}$ \\
\hline$P_{\mathrm{gm}}$ & Girder membrane resistance & $\mathrm{MN}$ \\
\hline$P_{\mathrm{p}}$ & Plating resistance & $\mathrm{MN}$ \\
\hline$P_{\text {loc }}$ & Local resistance of the gate & $\mathrm{MN}$ \\
\hline
\end{tabular}

The analysis by Simonsen [8] of the deep collapse of deck or girders subjected to an in-plane, concentrated load, is the basis for the development in the present work of local dissipation in the horizontal girders of the gate. The influence of the bow tip radius is moreover taken into account, using some elements of Ohtsubo's modelling [9] of inner dynamics of ship side collision to bridge pier (in the present work, the striking bow is viewed as the bridge pier, whereas the gate is viewed as the ship side). The local dissipation by bending and tension of the gate plating, uses the similar developments of Zhang [5] in its analysis of the mechanics of ships collision. Coupling between energy dissipations in the girders and in the plating is achieved by minimisation of the whole energy dissipated in both structures. The deformation spreading from the initial impacted macro-element to adjacent ones, is based on Wierzbicki [4] global structural modelling of bow indentation into ship side.

The global bending mode of the gate is simplified as a bending mode around plastic hinges determined by the bow shape. The correspondent dissipated energy derives from the fully plastic bending moment of the gate. This one is computed by assuming that the gate is subjected to pure bending around a vertical axis located in the plane of impact, perpendicular to the gate (see Appendix A).

\section{Description of the structures}

Driven by rollers, the gate is lifted out of its seating by two chains hooked on each side. Its main characteristics are the following:

Table 1. Main characteristics of the lock gate.

\begin{tabular}{cccc}
\hline Length & Height & Mass & Material \\
\hline $12.7 \mathrm{~m}$ & $7 \mathrm{~m}$ & 45 tons & mild steel \\
\hline
\end{tabular}


Table 2. Main characteristics of the striking river ship.

\begin{tabular}{lcc}
\hline & Rhône-Liner Carrier & Passenger vessel \\
\hline Length $(\mathrm{m})$ & 79 & 118 \\
Breadth $(\mathrm{m})$ & 10.9 & 11 \\
Laden displacement (tons) & 3500 & 2210 \\
Draught (m) & 3.3 & 2.2 \\
Stem angle & $30^{\circ}$ & $30^{\circ}$ \\
Bow angle & $92^{\circ}$ & $70^{\circ}$ \\
Bow rounding radius $(\mathrm{m})$ & 0.5 & 1.3 \\
Bulb horizontal radius $(\mathrm{m})$ & 0.4 & \\
Bulb vertical radius $(\mathrm{m})$ & 1.0 & \\
\hline
\end{tabular}

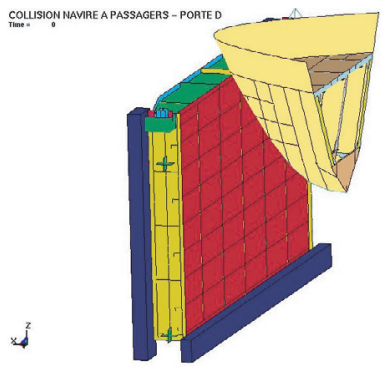

Fig. 1. Carrier impact.

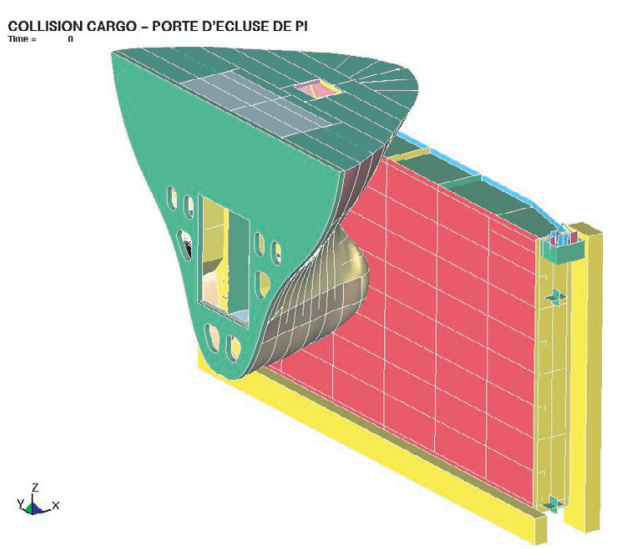

Fig. 2. Passenger vessel impact.

Collision scenarios are presented in Figure 1 for the Carrier Rhône liner and in Figure 2 for the passenger vessel. In both cases, the strinking ship impacts the lock gate perpendicularly between two vertical stiffeners, at $1 \mathrm{~m} . \mathrm{s}^{-1}$ for the carrier and at $2 \mathrm{~m} . \mathrm{s}^{-1}$ for the passenger ship. The main characteristics of both ships are listed in Table 2.

\section{Numerical analysis}

The impact between the lock gate and river ships is a crash problem governed by buckling, yielding, rupture of materials and assemblies. Elasto-plastic finite element analysis was carried out by using the explicit FEA program LS-DYNA [10]. The finite element meshes of the gate and of the ships were built using Ideas Master Series $^{\text {TM }}$ as a preprocessor of LS-DYNA ${ }^{\mathrm{TM}}$. Underintegrated shell elements using five Gauss integration points through the thickness were used. The medium size of a shell element was about $8 \mathrm{~cm}$ near the impact zone, $10 \mathrm{~cm}$ at mid-gate and $12 \mathrm{~cm}$ at the bottom. The hauling system was represented by three rigid beams on each side and the gate is simply supported in all directions. The concrete frame of the lock was modeled by a clamped rigid body. The hydrostatic pressure in the lower part of the gate, negligible compared to the impact force, was not taken into account.

In Figure 3a, the indentation of the carrier into the gate and the resulting effective plastic strains are shown. The vessel is intentionally shifted from the gate center in order to simulate the worse impact case. Actually, this position is determined from the breadths of the vessel and of the lock, and leads to an impact located in the middle of the two vertical stiffeners. In this case, the lock gate is impacted by both the bow and the bulbous of the cargo-liner. This double impact leads to a local plastic hinge extending from the bottom to the top and a global bending of the lock gate. Figure $3 \mathrm{~b}$ presents a view of the effective plastic strains in the lock gate when it is impacted by the passenger vessel at $v_{0}=2 \mathrm{~m} . \mathrm{s}^{-1}$. The results analysis shows the global bending of the lock gate added to a local folding of the horizontal stiffeners and buckling of the vertical ones.

\section{Analytical analysis}

\subsection{Introduction}

The analytical model is developed according to the following principle:

i. a global bending energy-deflection relationship is seeked, from which a global bending resistance will be found;

ii. a local energy-deflection relationship is then developed from which a local resistance will derive. Failure in structures (plating or girders) can be detected by a critical rupture strain criteria;

iii. the impact force, is defined for each deflection value, as the minimum of these two components.

The computation goes on, while the energy dissipation in the gate is lower than the initial ship kinetic energy. Actions on bearings are determined from the impact force assimilated to a quasi-static load and by assuming linear distributions along the bearings. 


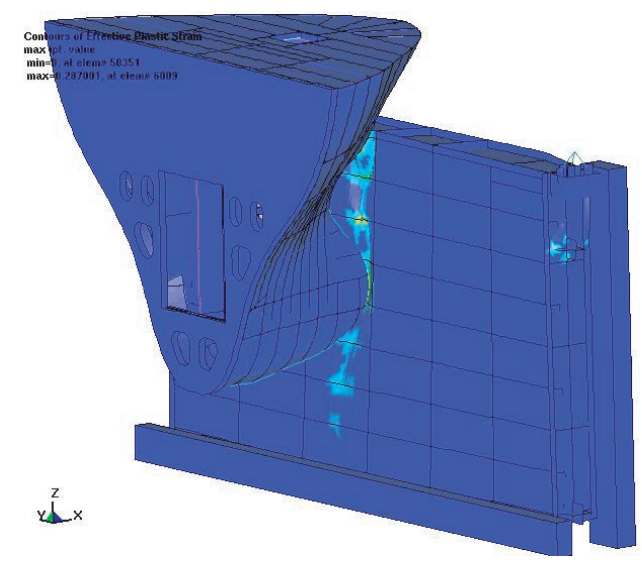

(a)
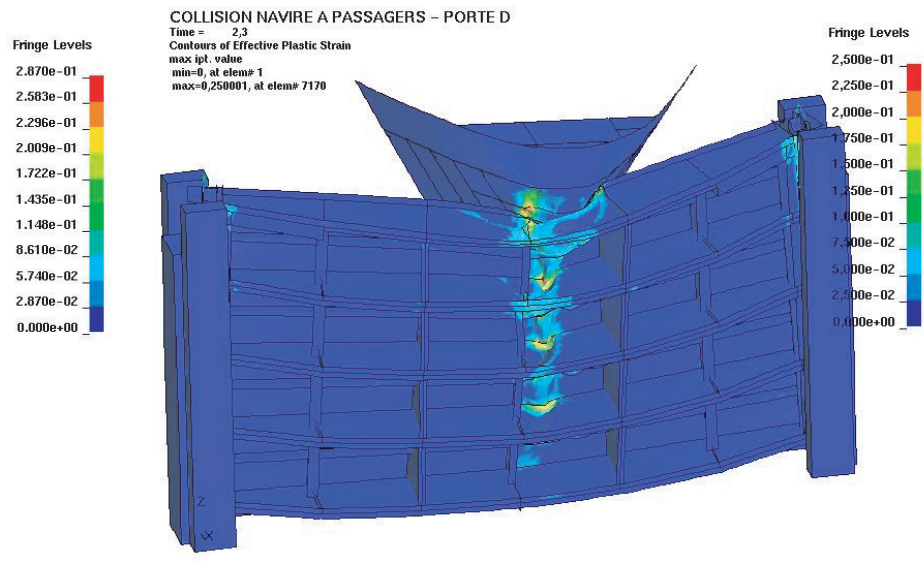

(b)

Fig. 3. Effective plastic strains at $t=1.96 \mathrm{~s}$ for the carrier impact (a), and for the passenger ship impact at $t=2.3 \mathrm{~s}$ (b).

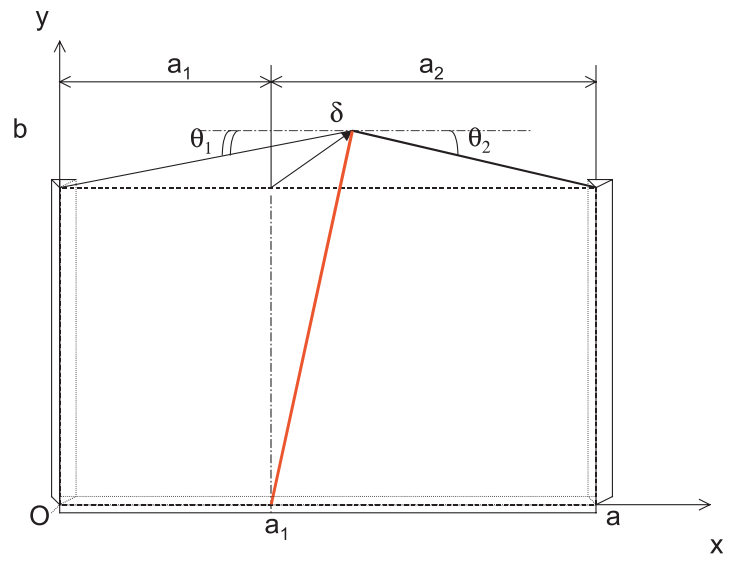

(a) Raked bow impact

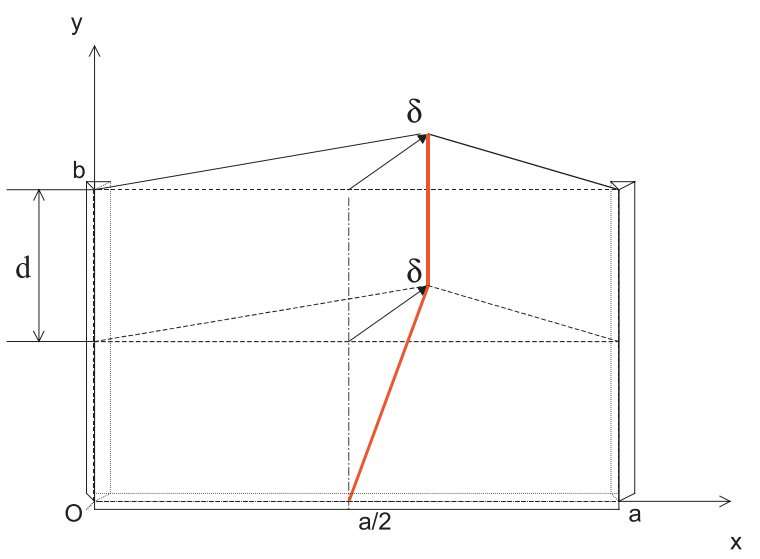

(b) Bulbous bow impact

Fig. 4. Assumed global deformation modes of the gate.

\subsection{Energy dissipation}

\subsubsection{Global bending dissipation}

The rigid bow is assumed to collide the lock-gate in a point of its upper edge located at distances $a_{1}$ and $a_{2}$ from extremities. The gate is modeled as a plate, length $a$, height $b$, simply supported on its lateral and lower bounds. Let us consider now the deformation of the same plate, firstly struck by the raked bow.

The following simple but realistic displacement field (Fig. 4a) is assumed:

$$
\begin{array}{lll}
w=\delta \frac{x}{a_{1}} \frac{y}{b} & \text { for } & 0 \leq x \leq a_{1} \\
w=\delta \frac{a-x}{a-a_{1}} \frac{y}{b} & \text { for } & a_{1} \leq x \leq a
\end{array}
$$

where $\delta=w\left(a_{1}, b\right)$ is the deflection at the impact point. It models a plastic hinge line located in the vertical plane of impact, with a linear variation of the rotation angle from the bottom to the top of the gate as it has been highlighted by the LS-DYNA results [10]. It satisfies also the boundary conditions.

In the case where the continuous deformation field (plate curvature) is neglected, the bending energy rate limited to the plastic hinge, can be expressed as:

$$
\dot{E}_{b}=\int_{0}^{l} \hat{M}_{0} \dot{\theta}_{1} \mathrm{~d} l+\int_{0}^{l} \hat{M}_{0} \dot{\theta}_{2} \mathrm{~d} l
$$

where $\hat{M}_{0}$ is the fully plastic bending moment per unit length of the plate (see Appendix A), $\theta_{1}, \theta_{2}$ and $l$ the local rotations and the length of the plastic hinge:

$$
\begin{array}{r}
\theta_{1}=\frac{w\left(a_{1}, y\right)}{a_{1}}=\frac{\delta}{a_{1}} \frac{y}{b} \quad \theta_{2}=\frac{w\left(a_{1}, y\right)}{a_{2}}=\frac{\delta}{a_{2}} \frac{y}{b} \\
l=\sqrt{b^{2}+\delta^{2}} \approx b\left(1+\frac{\delta^{2}}{2 b^{2}}\right)
\end{array}
$$


If the structure of the gate can be considered as uniform along the plastic hinge (as the case for the considered gate), $\hat{M}_{0}$ is constant and:

$$
\begin{aligned}
\dot{E}_{\mathrm{b}} & =\hat{M}_{0}\left[\int_{0}^{l} \dot{\theta}_{1} \mathrm{~d} l+\int_{0}^{l} \dot{\theta}_{2} \mathrm{~d} l\right] \\
& =\hat{M}_{0} \frac{b}{2}\left(\frac{1}{a_{1}}+\frac{1}{a_{2}}\right)\left(1+\frac{\delta^{2}}{2 b^{2}}\right) \dot{\delta}
\end{aligned}
$$

Finally, the global bending energy of the gate is:

$$
\begin{aligned}
E_{\mathrm{b}} & =\int_{0}^{t} \dot{E}_{\mathrm{b}} \mathrm{d} t=\int_{0}^{\delta} \hat{M}_{0} \frac{b}{2}\left(\frac{1}{a_{1}}+\frac{1}{a_{2}}\right)\left(1+\frac{\delta^{2}}{2 b^{2}}\right) \mathrm{d} \delta \\
& =\hat{M}_{0} \frac{a b}{2 a_{1} a_{2}}\left(1+\frac{\delta^{2}}{6 b^{2}}\right) \delta
\end{aligned}
$$

and its resistance derived from (5):

$$
P_{\mathrm{b}}=\frac{\dot{E}_{\mathrm{b}}}{\dot{\delta}}=\hat{M}_{0} \frac{a b}{2 a_{1} a_{2}}\left(1+\frac{\delta^{2}}{2 b^{2}}\right)
$$

With the previously formulated assumptions, $M_{0}$ is obtained from $\hat{M}_{0}: M_{0}=l \hat{M}_{0}$, where $l$ is given by Equation (4), so that the gate resistance in its global bending mode is:

$$
P_{\mathrm{b}}=\frac{M_{0} a}{2 a_{1} a_{2}}
$$

For the bulbous bow impact, a similar development based on the global deformation mode shown in Figure 4b, yields:

$$
P_{\mathrm{b}}=2 \frac{M_{0}}{a_{1} a_{2}}\left[1+d\left(b+\frac{\delta^{2}}{2(b-d)}\right)^{-1}\right]
$$

The resistance of the considered gate impacted, for example at 0.60 meter from its midst point $\left(a_{1}=\right.$ $5.75 \mathrm{~m} \quad a_{2}=6.95 \mathrm{~m}$ ), is then: $P_{\mathrm{b}} \approx 2.26 \mathrm{MN}$ in the case of the raked bow and $P_{\mathrm{b}} \approx 3.31 \mathrm{MN}$ in the case of the bulbous bow $(d=3.25 \mathrm{~m})$. In both cases, it can be considered as constant with indentation.

\subsubsection{Local dissipation}

Figure 5 presents the macro-element involved at the beginning of the impact. The rigid raked bow collides the lock-gate on its uppermost girder near the median transverse frame at a distance $a_{2}$ from this latter.

The first deformations include at the same time:

i. the bending and the tension of the plating part, delimited by its transverse frames, the uppermost girder and the next lower girder. Transverse frames and the low girder are assumed to be at first stage rigid, so that the plating and the uppermost girder can be considered first as perfectly clamped. With the increase of transverse deformation, the relative contribution of the bending force becomes very weak. Therefore, only the membrane forces are considered in the plating;

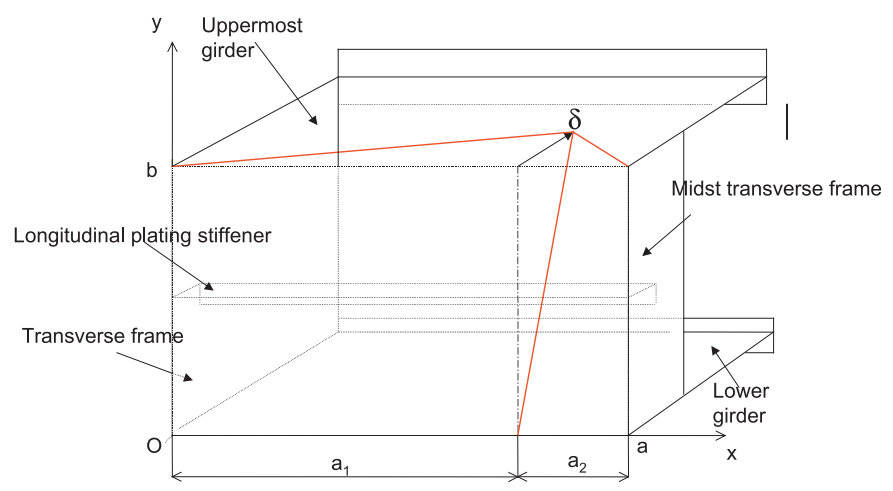

Fig. 5. Zoom on the impact location at the uppermost girder of the gate.

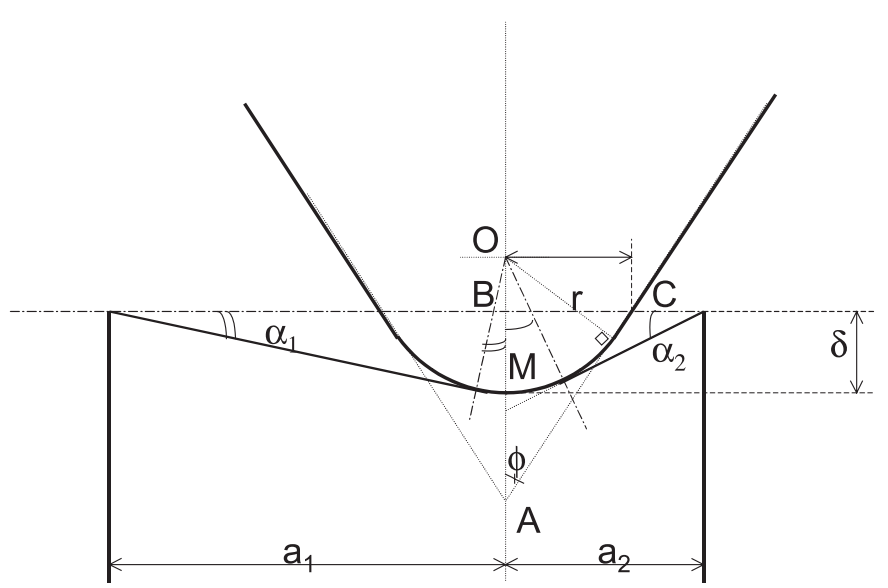

Fig. 6. Impact by a rounded bow.

ii. the uppermost girder crushing (buckling and folding); iii. the buckling of the plating longitudinal stiffener. Because of its low scantlings, its own deformations are not specifically studied. It will be taken into account by distributing its cross-sectional area into the plating.

\subsubsection{Resistance of initial macro-element}

Most of bow tips are rounded with a radius $r$. Their contact with the gate along the horizontal uppermost girder is assumed to be uniform (Ohtsubo [9]), so that the gate material wraps perfectly around them (Fig. 6). Energy is absorbed in the girder web by bending at a rate of $\dot{E}_{\mathrm{gb}}$ and by membrane deformations at a rate of $\dot{E}_{\mathrm{gm}}$.

Assuming the same deformation mode (Fig. 7a) identified by Simonsen [8], for the uppermost girder crushing subjected to an in-plane concentrated load, the indentation $\delta$ derives on one hand from geometry in the horizontal plane (Fig. 6):

$$
\delta=a_{1} \operatorname{tg} \alpha_{1}+r\left(1-\frac{1}{\cos \alpha_{1}}\right)=a_{2} \operatorname{tg} \alpha_{2}+r\left(1-\frac{1}{\cos \alpha_{2}}\right)
$$

$\delta \approx a_{1} \alpha_{1}-\frac{r}{2} \alpha_{1}^{2}+\frac{a_{1}}{3} \alpha_{1}^{3} \approx a_{2} \alpha_{2}-\frac{r}{2} \alpha_{2}^{2}+\frac{a_{2}}{3} \alpha_{2}^{3}$ 


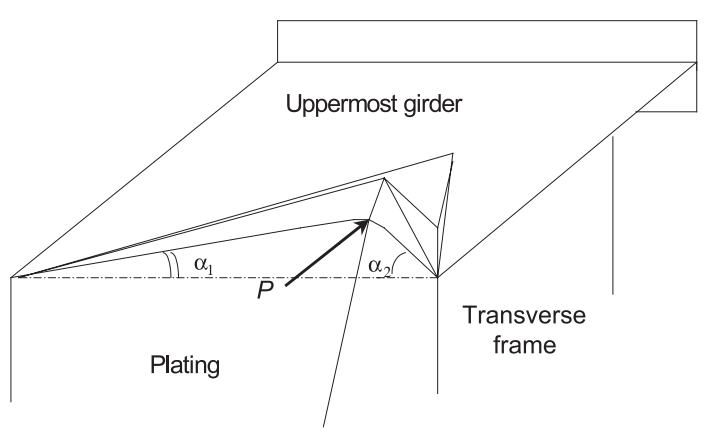

(a)

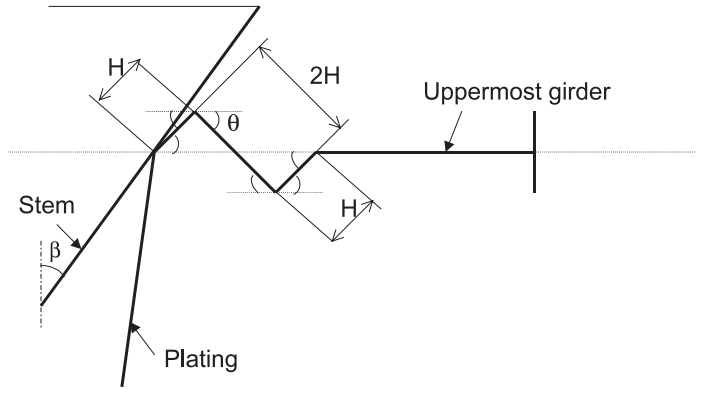

(b)

Fig. 7. (a) Deformation mode of the uppermost girder. (b) Deformation mode of the uppermost girder.

and on the other hand from the plastic hinges rotation $\theta$ (Fig. 7b) by the relation:

$$
\delta=4 H(1-\cos \theta)
$$

where $4 H$ is the folding length, which is assumed to be shallow $\left(4 H \ll a_{1}, a_{2}\right)$.

The mean local crushing force for the complete compression of first fold $(\theta=\pi / 2)$ is expressed as:

$$
\bar{P}_{\mathrm{loc}}=\frac{E_{\mathrm{gm}}+E_{\mathrm{gb}}+E_{\mathrm{p}}}{4 H}
$$

$E_{\text {gm }}$ and $E_{\text {gb }}$ are the correspondent membrane and bending energy dissipated in the girder [8], and $E_{\mathrm{p}}$ is the correspondent membrane energy dissipated in the plating [5].

$H$ is obtained by minimizing this force:

$$
\frac{\partial \bar{P}_{\mathrm{loc}}}{\partial H}=0 \Rightarrow H
$$

The instantaneous local crushing force can be consequently calculated from the different resistances:

$$
P_{\mathrm{loc}}(\delta)=P_{\mathrm{gb}}+P_{\mathrm{gm}}+P_{\mathrm{P}}
$$

Girder bending resistance is given by [8]:

$$
P_{\mathrm{gb}}=\frac{\dot{E}_{\mathrm{gb}}}{\dot{\delta}}=\frac{3 M_{0}\left(a_{1}+a_{2}\right)}{2 H}\left[1-\left(1-\frac{\delta}{4 H}\right)^{2}\right]^{-1 / 2}
$$

with: $M_{0}=\frac{2}{\sqrt{3}} \frac{\sigma_{0} t_{\mathrm{g}}^{2}}{4}$ the fully plastic bending moment of the girder web, $t_{\mathrm{g}}$ its thickness.

Girder membrane resistance is (see Appendix B):

$$
\begin{aligned}
P_{\mathrm{gm}} & =\frac{\dot{E}_{\mathrm{gm}}}{\dot{\delta}} \\
& =\frac{11}{4} \sigma_{0} t_{\mathrm{g}} H\left[\frac{a_{1} \alpha_{1}-r \alpha_{1}^{2}}{a_{1}-r \alpha_{1}+a_{1} \alpha_{1}^{2}}+\frac{a_{2} \alpha_{2}-r \alpha_{2}^{2}}{a_{2}-r \alpha_{2}+a_{2} \alpha_{2}^{2}}\right]
\end{aligned}
$$

Plating resistance is (see Appendix C):

$$
P_{\mathrm{p}}=\frac{8}{15 \sqrt{3}} \sigma_{0} t \delta a b\left(\frac{1}{a_{1} a_{2}}+\frac{1}{b^{2}}\right)
$$

Several folds of the uppermost girder can be so created.

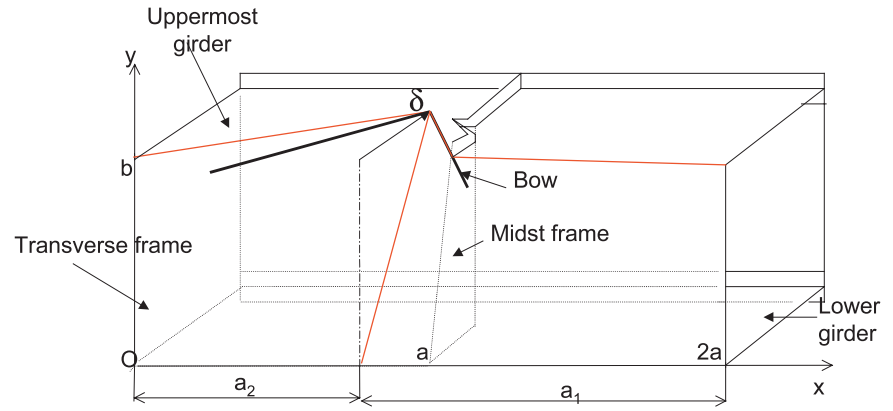

Fig. 8. New macro-element involved by the bow contact with the midst frame.

\subsubsection{Impact force subsequent evolution}

When the bow reaches the transverse frames or the lower girder of the initial impacted macro-element, a second phase begins. For instance, if the bow touches the midst transverse frame in point $\mathrm{C}$, located at the intersection between this latter, the uppermost girder and the plating, the midst frame will be crushed and a new macroelement will be involved (Fig. 8). New deformation modes for the uppermost girder and for the plating appear.

The crushing force is now the resultant of:

i. the resistance of the initially collided plating piece;

ii. the resistance of the new collided plating piece;

iii. the resistance $F$ of the $T$ super-element, made of the uppermost girder and the midst transverse frame.

As Wierzbicki and Simonsen [4] did for their structural model of bow indentation into a ship side, the deformation spreading from the initial impacted macro-element to the adjacent one is based on mechanical equilibrium at the intersection between transverse frame, uppermost girder and plating (point $\mathrm{C}$ ):

$$
F=T_{2} \sin \alpha_{2}-T^{\prime} \sin \beta
$$

where $F$ is assumed to be normal to the gate plane (Fig. 9), and $T_{2}$ and $T^{\prime}$ are the axial forces in the plating on each side of the frame. Since the plastic zone spreads on each side of the frame, $T_{2}$ and $T^{\prime}$ are assumed to be equal to the full plastic strength: $N_{0}=\sigma_{0} b t$. 


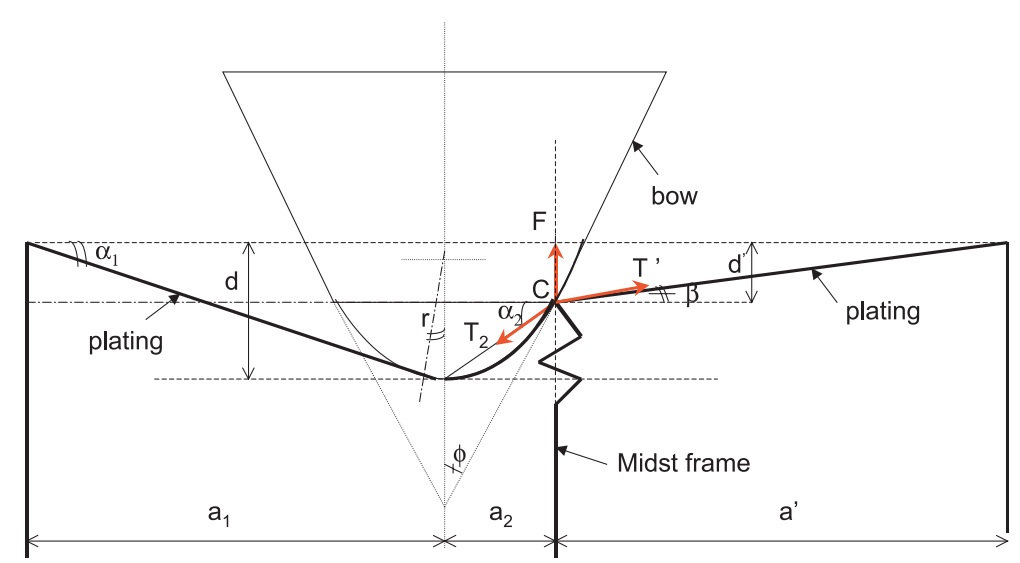

Fig. 9. Deformation spreading to the adjacent macro-element after contact between the bow and the midst frame.

\section{Comparison of analytical results with numerical ones}

\subsection{Impact by the passenger vessel}

The bow features are:

- stem angle: $30^{\circ}$;

- bow angle: $70^{\circ}$;

- bow rounding radius at impact location: $1.3 \mathrm{~m}$.

The lock-gate is stroke with initial velocities of $1 \mathrm{~m} \cdot \mathrm{s}^{-1}$ or $2 \mathrm{~m} . \mathrm{s}^{-1}$. The impact location is shifted of $0.60 \mathrm{~m}$ from the gate center. Actually, this position is determined by the breadths of the vessel and of the lock and yields an impact located in the middle of two vertical stiffeners, occurring the worse impact case for the gate.

Figure 10 reveals that:

- the maximum value reached by the impact force assessed by the analytical model is rather close to that given by LS-DYNA [11];

- the impact force is firstly decreasing in the analytical model, instead of beginning from zero. It is due to the modeling of the bending force in the uppermost girder web during its first fold compression;

- the maxima indentations obtained at the impact point match very well for both considered impact velocities: $0.65 \mathrm{~m}$ for $1 \mathrm{~m} . \mathrm{s}^{-1}$ and $2.25 \mathrm{~m}$ for $2 \mathrm{~m} . \mathrm{s}^{-1}$;

- the collision returned account by the analytical model appears harder, the rise of impact force being stiffer;

- the impact velocity, which by principle of the analytical model, does not have any influence on the shape of the curve impact force versus indentation (the dynamic effects are not taken into account), also practically does not have any one on the shape of the numerical curves. One cannot however generalize this property for higher velocities.

Figure 11 shows the linear densities of the reactions on the uppermost and on the lowermost parts of the vertical bearings. The reactions given by the analytical model were assessed by assuming a linear distribution of the reactions whereas LS-DYNA gives an account of a nonlinear distribution $[7,11]$. This can explain the significant differences in term of shape or level.

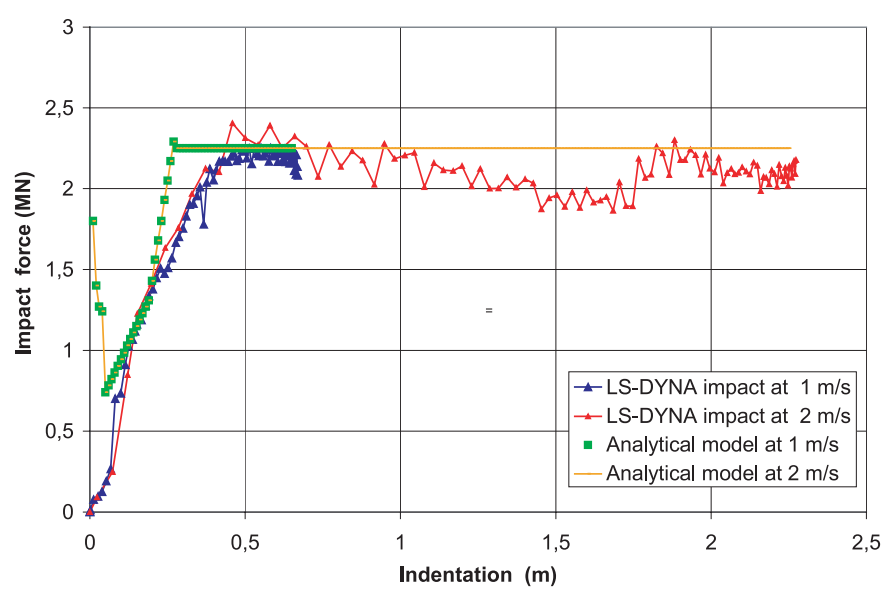

Fig. 10. Impact forces comparison.

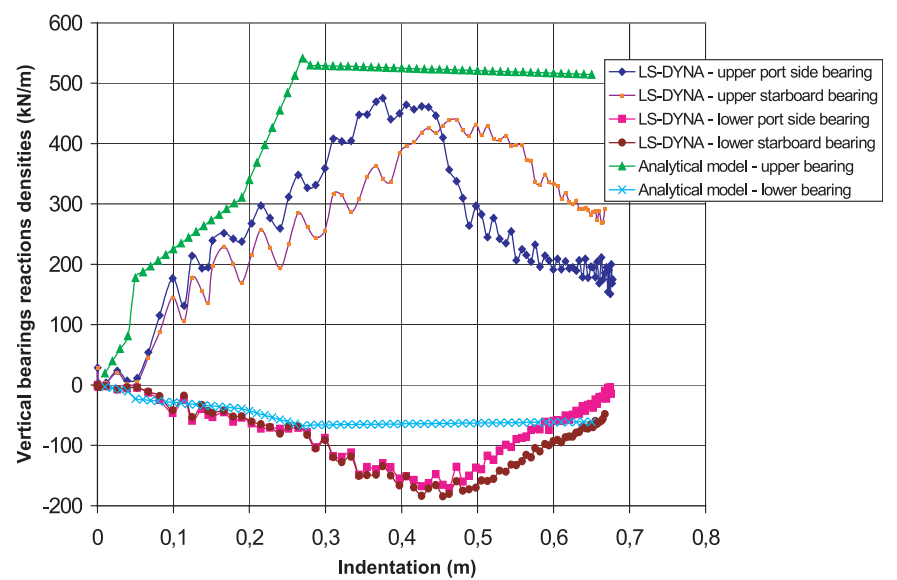

Fig. 11. Comparison of actions on the vertical bearings.

Figure 12 shows the actual actions on the suspensions (chains and cables linked to the lift motor and the counter-weights), which are the absolute values of the difference between the calculated actions and the sum of the gate weight: 56 tons, and the friction vertical component due to the hydrostatic thrust. We can notice that the analytical model clearly raises the actions calculated by LS-DYNA. The friction coefficient between the gate 


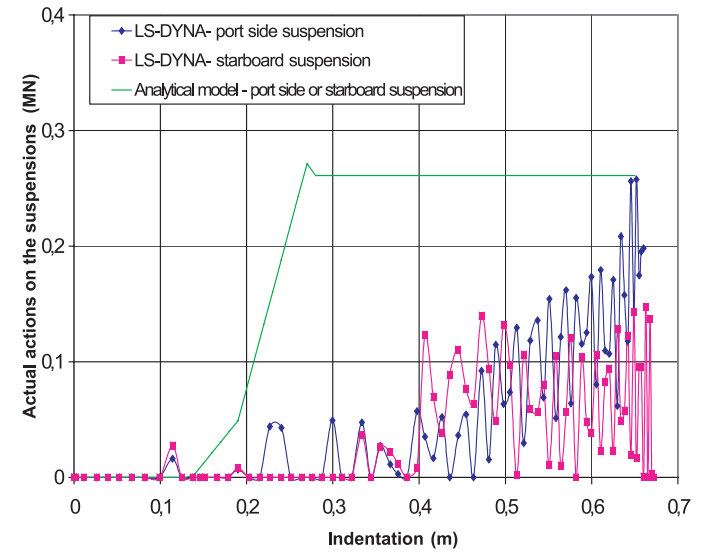

(a)

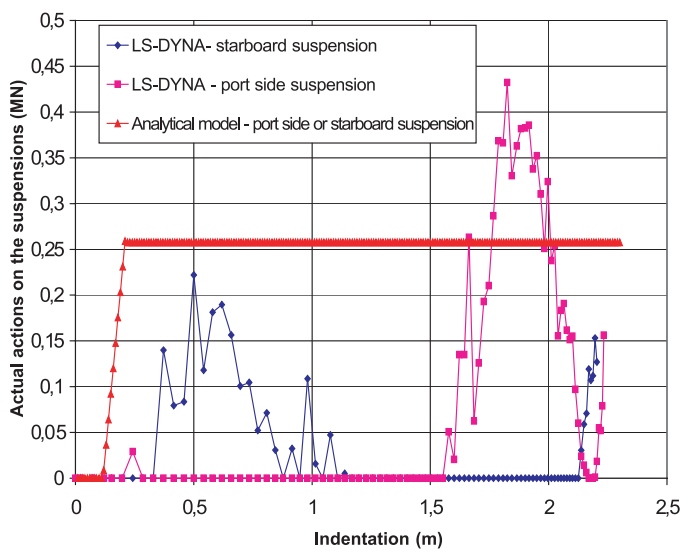

(b)

Fig. 12. Comparison of actions on the suspensions for impact velocities of $1 \mathrm{~m} \cdot \mathrm{s}^{-1}$ (a) and $2 \mathrm{~m} \cdot \mathrm{s}^{-1}$ (b).

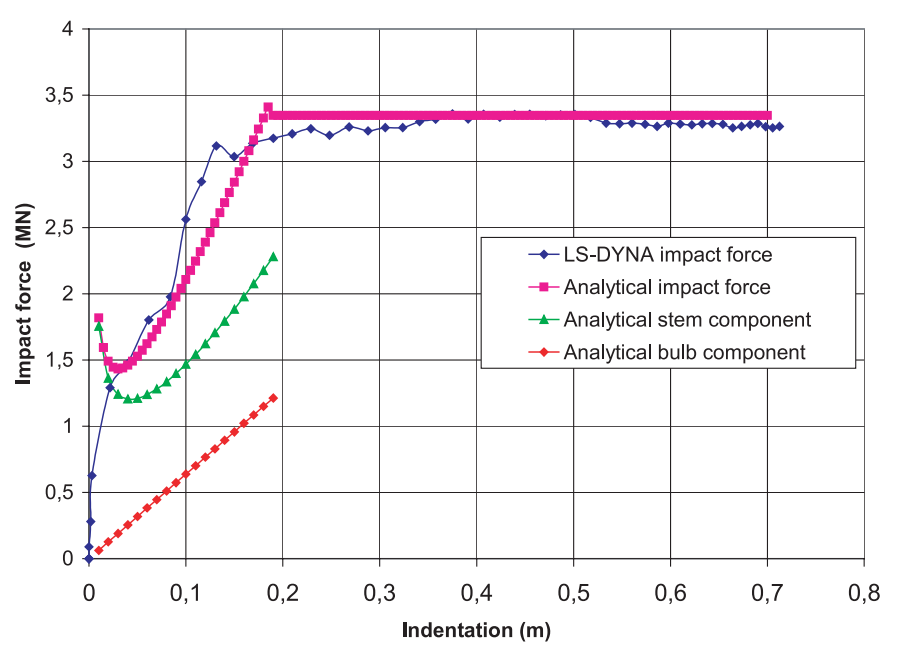

Fig. 13. Impact forces comparison at $1 \mathrm{~m} \cdot \mathrm{s}^{-1}$.

and the vessel, in both calculation cases, is: 0.1. Whereas LS-DYNA differentiates the actions with port side and with starboard, because of the decentring of the impact, the analytical model assumes the symmetry of these actions. What shows Figure 12b, does not make possible to conclude on coherence from analytical results on one hand and finite elements on the other hand. This is due to the dissymmetry of actions with port side and starboard due to decentring of impact.

\subsection{Impact by the Rhône-Liner carrier}

The bulbous bow features are:

- stem angle: $30^{\circ}$;

- bow angle: $92^{\circ}$;

- bow rounding radius at impact location: $0.5 \mathrm{~m}$;

- vertical radius of the bulb: $1.0 \mathrm{~m}$;

- horizontal radius of the bulb: $0.4 \mathrm{~m}$;

- bulb length: $0.4 \mathrm{~m}$.

Regarding the analytical results, Figure 13 shows the impact force and for the first stage of the collision, its both components exerted simultaneously, on one hand by the stem, and on the other hand by the bulb. It reveals that:

- the maximum value reached by the impact force assessed by the analytical model is almost constant and is rather closed to that given by LS-DYNA;

- the maxima indentations match rather well around $0.70 \mathrm{~m}$.

\section{Conclusion}

An analytical model for plane lock gates crashworthiness has been developed. The ships are assumed to be quite rigid with respect to the gate. Results of impact of one given lock gate with two different ships: a passenger vessel and a carrier, are compared with FEM results. Impact forces and maximum indentation are well matched. Actions on bearings can be locally rather different because of dynamical effects and the non-linearity of their distributions, two factors not taken into account in the analytical model. Compared with finite element analysis, this analytical model developed with Matlab on PC (Windows 98) is a very fast and effective simulation tool for crash parametric studies. On the basis of the present modelling, taking into account non-plane geometry, particularly mitre gates, will be the next stage of this work.

\section{Appendix A: Fully plastic bending moment assessment}

Any gate can be considered as the assembly of several horizontal elementary beams. Regarding the considered gate, its structure, rather simple, consists in four identical ones presented in Figure A.1. By assuming that all these beams are only submitted to bending around a vertical axis, the fully plastic bending moment of the gate is equal 


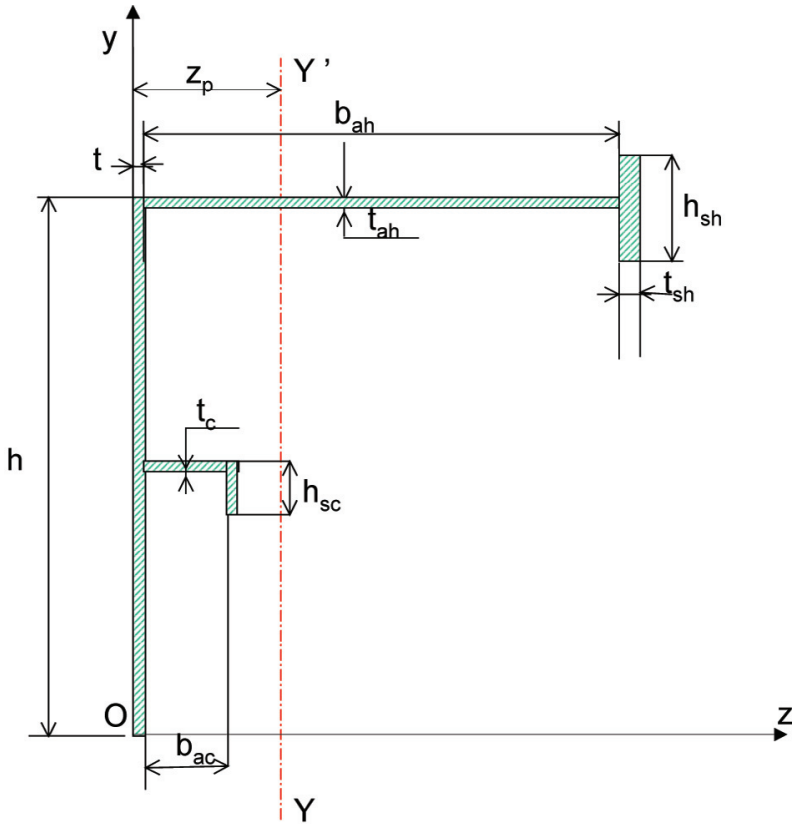

Fig. A.1. Elementary beam submitted to bending around vertical axis.

to four times the fully plastic bending moment of one elementary beam: $M_{\mathrm{p}}=4 m_{\mathrm{p}}$ with:

$$
m_{\mathrm{p}}=\int_{S_{+}} \sigma_{\mathrm{y}}\left(z_{\mathrm{p}}-z\right) \mathrm{d} s+\int_{S_{-}} \sigma_{\mathrm{y}}\left(z-z_{\mathrm{p}}\right) \mathrm{d} s
$$

where $S_{+}$et $S_{-}$are the cross-sections located on both sides of the plastic neutral axis $Y^{\prime} Y, z$ the second coordinate in the beam cross-section, $z_{\mathrm{p}}$ the coordinate of the plastic neutral axis and $\sigma_{\mathrm{y}}$ the absolute value of the yield stress.

In the case of pure bending, the normal force is equal to zero:

$0=\int_{S} \sigma_{\mathrm{y}} \mathrm{d} s=\int_{S_{+}} \sigma_{\mathrm{y}} \mathrm{d} s+\int_{S_{-}}\left(-\sigma_{\mathrm{y}}\right) \mathrm{d} s=\int_{S_{+}} \sigma_{\mathrm{y}} \mathrm{d} s-\int_{S_{-}} \sigma_{\mathrm{y}} \mathrm{d} s$

If the gate material is homogeneous, we have:

$$
\begin{aligned}
\int_{S_{+}} \sigma_{\mathrm{y}} \mathrm{d} s+\int_{S_{-}} \sigma_{\mathrm{y}} \mathrm{d} s & =\sigma_{\mathrm{y}}\left(\int_{S_{+}} \mathrm{d} s+\int_{S_{-}} \mathrm{d} s\right) \\
& =\sigma_{\mathrm{y}} \sum_{i} S_{i}=N_{\mathrm{p}}
\end{aligned}
$$

where $S_{i}$ are the sections of the different parts of the beam: plating, webs and flanges of the different plating stiffeners, and $N_{\mathrm{p}}$ is the fully plastic normal force.

From (2) and (3) we get:

$$
\int_{S_{-}} \sigma_{\mathrm{y}} \mathrm{d} s=\frac{N_{\mathrm{p}}}{2}
$$

Several cases can occur according to the plastic neutral axis location with regard to the different components of the beam. The first one occurs when: $\sigma_{\mathrm{y}} S_{\mathrm{b}} \geq \frac{N_{\mathrm{p}}}{2}$ where $S_{\mathrm{b}}$ is the plating cross-section; then $S_{-}$is a part of the plating and:

$$
\int_{S_{-}} \sigma_{\mathrm{y}} \mathrm{d} s=\sigma_{\mathrm{y}} h z_{\mathrm{p}}=\frac{N_{\mathrm{p}}}{2} \Rightarrow z_{\mathrm{p}}=\frac{N_{\mathrm{p}}}{2 \sigma_{\mathrm{y}} h}
$$

This case is the most usual one and the considered neutral axis is in this one: $z_{\mathrm{p}}=0.0113 \mathrm{~m}$ (the plating is $0.0150 \mathrm{~m}$ thick). The fully plastic bending moment is given by Equation (1): $m_{\mathrm{p}}=2.37 \mathrm{MNm}$.

In order to take into account the material hardening during its plastic straining, the flow stress is chosen to be constant and equal to the average: $\sigma_{0}=\frac{\sigma_{\mathrm{y}}+\sigma_{\mathrm{u}}}{2}$ and the fully plastic bending moment becomes: $m_{0}=\frac{\sigma_{0}}{\sigma_{\mathrm{y}}} m_{\mathrm{p}}$.

For the considered A48 steel material, $\sigma_{\mathrm{y}}=210 \mathrm{MPa}$ and $\sigma_{\mathrm{u}}=420 \mathrm{MPa}$, so that: $\sigma_{0}=415 \mathrm{MPa}, m_{0}=$ 3.56 MNm and for the whole gate: $M_{0}=4 m_{0}=$ $14.24 \mathrm{MNm}$.

\section{Appendix B: Girder resistance}

Using Figure 6 in main text, the strain of the outer fiber on left side is:

$$
\begin{aligned}
\varepsilon_{01} & =\frac{1}{a_{1}}\left[\frac{a_{1}}{\cos \alpha_{1}}-r \operatorname{tg} \alpha_{1}+r \alpha_{1}-a_{1}\right] \\
& \approx \frac{1}{\cos \alpha_{1}}-\frac{r}{a_{1}} \frac{\alpha_{1}^{3}}{3}-1 \approx \frac{\alpha_{1}^{2}}{2}-\frac{r}{a_{1}} \frac{\alpha_{1}^{3}}{3}
\end{aligned}
$$

and its strain rate is:

$$
\dot{\varepsilon}_{01} \approx \alpha_{1}\left(1-\frac{r}{a_{1}} \alpha_{1}\right) \dot{\alpha}_{1}
$$

On the right side it is similarly:

$$
\dot{\varepsilon}_{02} \approx \alpha_{2}\left(1-\frac{r}{a_{2}} \alpha_{2}\right) \dot{\alpha}_{2}
$$

The correspondent elongation rates are:

$$
\dot{u}_{01}=a_{1} \dot{\varepsilon}_{01} \quad \text { and } \quad \dot{u}_{02}=a_{2} \dot{\varepsilon}_{02}
$$

The membrane energy dissipation is given by the model of Simonsen [8]:

$$
\begin{aligned}
\dot{E}_{\mathrm{gm}}= & \frac{11}{4} N_{0} H\left(\dot{u}_{01}+\dot{u}_{02}\right) \\
= & \frac{11}{4} \sigma_{0} t_{\mathrm{g}} H\left[a_{1} \alpha_{1}\left(1-\frac{r}{a_{1}} \alpha_{1}\right) \dot{\alpha}_{1}\right. \\
& \left.+a_{2} \alpha_{2}\left(1-\frac{r}{a_{2}} \alpha_{2}\right) \dot{\alpha}_{2}\right]
\end{aligned}
$$

$N_{0}=\sigma_{0} t_{\mathrm{g}}$ is the fully plastic axial force per unit length of the girder. 
The energy dissipation at complete compression of first fold $(\delta=4 H)$ is:

$$
\begin{aligned}
E_{\mathrm{gm}}=\int_{0}^{t} \dot{E}_{\mathrm{gm}} \mathrm{d} t= & \frac{11}{4} \sigma_{0} t_{\mathrm{g}} H\left[a_{1}\left(\frac{\alpha_{1 \max }^{2}}{2}-\frac{r}{3 a_{1}} \alpha_{1 \max }^{3}\right)\right. \\
& \left.+a_{2}\left(\frac{\alpha_{2 \max }^{2}}{2}-\frac{r}{3 a_{2}} \alpha_{2 \max }^{3}\right)\right]
\end{aligned}
$$

where $\alpha_{1 \max }$ and $\alpha_{2 \max }$ are the values of $\alpha_{1}$ and $\alpha_{2}$ for: $\delta=4 H$.

Using Equation (11) in main text, we get:

$$
\dot{\delta} \approx\left(a_{1}-r \alpha_{1}+a_{1} \alpha_{1}^{2}\right) \dot{\alpha}_{1} \approx\left(a_{2}-r \alpha_{2}+a_{2} \alpha_{2}^{2}\right) \dot{\alpha}_{2}
$$

Then, Equation (6) can be written:

$\dot{E}_{\mathrm{gm}}=\frac{11}{4} \sigma_{0} t_{\mathrm{g}} H\left[\frac{a_{1} \alpha_{1}-r \alpha_{1}^{2}}{a_{1}-r \alpha_{1}+a_{1} \alpha_{1}^{2}}+\frac{a_{2} \alpha_{2}-r \alpha_{2}^{2}}{a_{2}-r \alpha_{2}+a_{2} \alpha_{2}^{2}}\right] \dot{\delta}$

and the correspondent instantaneous local resistance is:

$$
\begin{aligned}
P_{\mathrm{gm}} & =\frac{\dot{E}_{\mathrm{gm}}}{\dot{\delta}} \\
& =\frac{11}{4} \sigma_{0} t_{\mathrm{g}} H\left[\frac{a_{1} \alpha_{1}-r \alpha_{1}^{2}}{a_{1}-r \alpha_{1}+a_{1} \alpha_{1}^{2}}+\frac{a_{2} \alpha_{2}-r \alpha_{2}^{2}}{a_{2}-r \alpha_{2}+a_{2} \alpha_{2}^{2}}\right]
\end{aligned}
$$

\section{Appendix C: Resistance of the plating piece initially impacted. Effective plastic strains}

The following displacement field satisfying the clamped boundary conditions, is assumed for the plating:

$$
\begin{array}{ll}
w=\delta\left(\frac{x}{a_{1}}\right)^{2}\left(\frac{y}{b}\right)^{2} & \text { for: } 0 \leq x \leq a_{1} \\
w=\delta\left(\frac{a-x}{a_{2}}\right)^{2}\left(\frac{y}{b}\right)^{2} & \text { for: } \quad a_{1} \leq x \leq a
\end{array}
$$

Using the Lagrangian strain tensor and neglecting the in-plane displacements, the strain components within the left part of the plating $\left(0 \leq x \leq a_{1}\right)$ derive from the above displacement field:

$$
\begin{aligned}
& \varepsilon_{x x}=\frac{1}{2}\left(\frac{\partial w}{\partial x}\right)^{2}=\frac{2 \delta^{2}}{a_{1}^{4} b^{4}} x^{2} y^{4} \\
& \varepsilon_{y y}=\frac{1}{2}\left(\frac{\partial w}{\partial y}\right)^{2}=\frac{2 \delta^{2}}{a_{1}^{4} b^{4}} x^{4} y^{2} \\
& \varepsilon_{x y}=\frac{1}{2} \frac{\partial w}{\partial x} \frac{\partial w}{\partial y}=\frac{2 \delta^{2}}{a_{1}^{4} b^{4}} x^{3} y^{3}
\end{aligned}
$$

so the strain rates within the considered part of plating, are:

$$
\begin{aligned}
& \dot{\varepsilon}_{x x}=\frac{4 \delta \dot{\delta}}{a_{1}^{4} b^{4}} x^{2} y^{4} \\
& \dot{\varepsilon}_{y y}=\frac{4 \delta \dot{\delta}}{a_{1}^{4} b^{4}} x^{4} y^{2} \\
& \dot{\varepsilon}_{x y}=\frac{4 \delta \dot{\delta}}{a_{1}^{4} b^{4}} x^{3} y^{3} \quad \text { we get: } \dot{\varepsilon}_{x y}^{2}=\dot{\varepsilon}_{x x} \dot{\varepsilon}_{y y}
\end{aligned}
$$

Using the Von Mises yield criterion, the rate of external loading must be equal to the rate of energy dissipation in the plating:

$$
\begin{aligned}
P_{1} \dot{\delta} & =\frac{2}{\sqrt{3}} \sigma_{0} t \iint_{S}\left[\dot{\varepsilon}_{x x}^{2}+\dot{\varepsilon}_{y y}^{2}+\dot{\varepsilon}_{x x} \dot{\varepsilon}_{y y}+\dot{\varepsilon}_{x y}^{2}\right]^{1 / 2} \mathrm{~d} s \\
& =\frac{2}{\sqrt{3}} \sigma_{0} t \iint_{S}\left(\dot{\varepsilon}_{x x}+\dot{\varepsilon}_{y y}\right) \mathrm{d} s \\
P_{1} \dot{\delta} & =\frac{2}{\sqrt{3}} \sigma_{0} t \frac{4 \delta \dot{\delta}}{a_{1}^{4} b^{4}} \iint_{S}\left(x^{2} y^{4}+x^{4} y^{2}\right) \mathrm{d} x \mathrm{~d} y
\end{aligned}
$$

$S$ is the plating area in the macro-element and $t$ is the equivalent plating thickness:

$$
t=t_{\mathrm{p}}+\frac{A_{\mathrm{s}}}{b}
$$

with $t_{\mathrm{p}}$ is the plating thickness and $A_{\mathrm{s}}$ the cross-sectional area of the stiffener.

So the resistance force of the considered part of plating is:

$$
\begin{aligned}
P_{1} & =\frac{2}{\sqrt{3}} \sigma_{0} t \frac{4 \delta}{a_{1}^{4} b^{4}}\left(\frac{a_{1}^{3}}{3} \frac{b^{5}}{5}+\frac{a_{1}^{5}}{5} \frac{b^{3}}{3}\right) \\
& =\frac{8}{15 \sqrt{3}} \sigma_{0} t \delta a_{1} b\left(\frac{1}{a_{1}^{2}}+\frac{1}{b^{2}}\right)
\end{aligned}
$$

For the second part of the plating, the resistance force is similarly:

$$
\begin{aligned}
P_{2} & =\frac{2}{\sqrt{3}} \sigma_{0} t \frac{4 \delta}{a_{2}^{4} b^{4}}\left(\frac{a_{2}^{3}}{3} \frac{b^{5}}{5}+\frac{a_{2}^{5}}{5} \frac{b^{3}}{3}\right) \\
& =\frac{8}{15 \sqrt{3}} \sigma_{0} t \delta a_{2} b\left(\frac{1}{a_{2}^{2}}+\frac{1}{b^{2}}\right)
\end{aligned}
$$

And for the whole plating, it becomes:

$$
\begin{aligned}
P_{\mathrm{p}} & =P_{1}+P_{2} \\
& =\frac{8}{15 \sqrt{3}} \sigma_{0} t \delta\left[a_{1} b\left(\frac{1}{a_{1}^{2}}+\frac{1}{b^{2}}\right)+a_{2} b\left(\frac{1}{a_{2}^{2}}+\frac{1}{b^{2}}\right)\right]
\end{aligned}
$$

Finally:

$$
P_{\mathrm{p}}=\frac{8}{\sqrt{3}} \sigma_{0} t \frac{\delta}{15} a b\left(\frac{1}{a_{1} a_{2}}+\frac{1}{b^{2}}\right)
$$



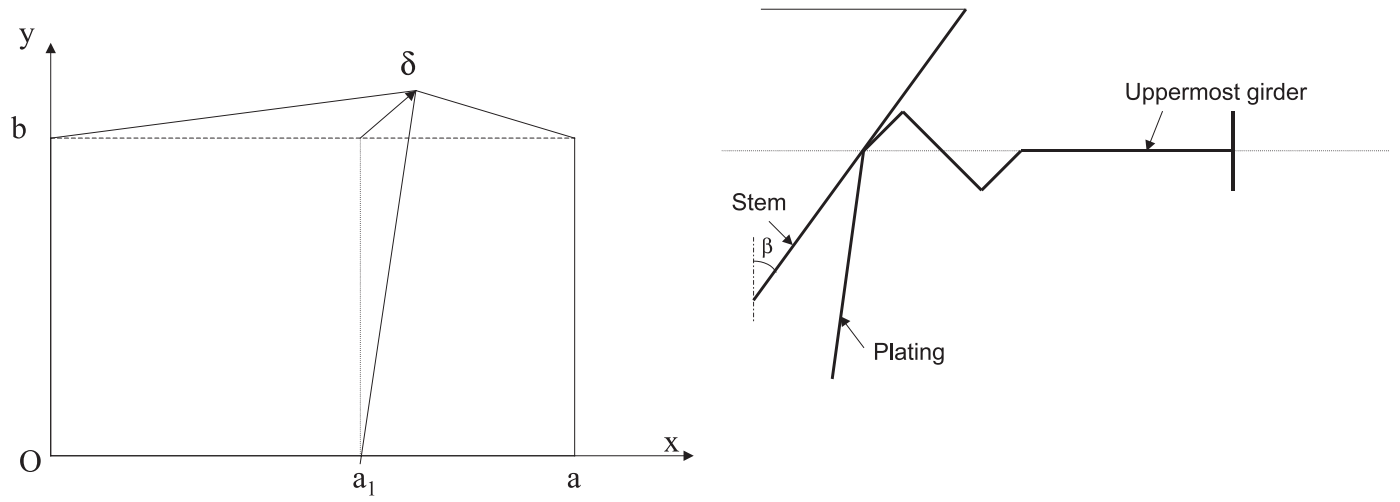

Fig. C.1. Plating deformation field at beginning of impact.

\section{Effective strains in the plating at impact point}

Using Equations (3)-(5) the strains at impact point on left side of this one, are:

$$
\varepsilon_{x x}\left(a_{1}, b\right)=\frac{2 \delta^{2}}{a_{1}^{2}} \quad \varepsilon_{y y}\left(a_{1}, b\right)=\frac{2 \delta^{2}}{b^{2}} \quad \varepsilon_{x y}\left(a_{1}, b\right)=\frac{2 \delta^{2}}{a_{1} b}
$$

The correspondent effective strain is:

$$
\varepsilon_{\mathrm{eff}_{1}}=\sqrt{\frac{2}{3}\left(\varepsilon_{x x}^{2}+\varepsilon_{y y}^{2}+2 \varepsilon_{x y}^{2}\right)}=\sqrt{\frac{8}{3}} \delta^{2}\left(\frac{1}{a_{1}^{2}}+\frac{1}{b^{2}}\right)
$$

On the right side of impact point it is equal to:

$$
\varepsilon_{\mathrm{eff}_{2}}=\sqrt{\frac{8}{3}} \delta^{2}\left(\frac{1}{a_{2}^{2}}+\frac{1}{b^{2}}\right)
$$

\section{References}

[1] H. Ohtsubo, The Crushing Mechanics of Bow Structure and Its Optimal Design against Head on Collision, Proceedings of PRADS 95, September 1995, pp. 2.1060-2.1069

[2] P.T. Pedersen, Absorbed Energy in Ship Collisions and Grounding - Revising Minorsky's Empirical Method, J. Ship Res. 44(2) (2000) 140-150
[3] B.C. Simonsen, Mechanics of Ship Grounding, Thesis, Department of Naval Architecture and Offshore Engineering, Technical University of Denmark, February 1997

[4] T. Wierzbicki, B.C. Simonsen, Global structural model of bow indentation into ship side, Technical Report, Department of Ocean Engineering, Massachusetts Institute of Technology, September 1996

[5] S. Zhang, The Mechanics of Ship Collisions, Thesis, Department of Naval Architecture and Offshore Engineering, Technical University of Denmark, January 1999

[6] J. McDermott, Tanker structure analysis for minor collisions, SNAME Transactions, 1974

[7] J.C. Rodet, Résistance aux chocs des portes amont des écluses. Simulations de collision, Technical Report, December 2000 (in French)

[8] B.C. Simonsen, H. Ocakli, Experiments and theory on deck and girder crushing, Thin Walled Structures 34 (1999) 195-216

[9] H. Ohtsubo, Inner dynamics of side collision to bridge piers, Ship Collision Analysis, Gluver \& Olsen (eds.) Balkema, Rotterdam, ISBN 9054109629

[10] J. Hallquist, LS-DYNA Theoretical Manual

[11] H. Le Sourne, Résistance au choc de la porte de Pierre Bénite heurtée par un bateau passagers, IRCN Technical Report, December 2000 (in French) 